\title{
The microencapsulation of mangosteen peel extract with maltodextrin from arenga starch: formulation and characterization
}

\author{
Andri Kusmayadi ${ }^{1,2^{*}}$, Lovita Adriani ${ }^{1}$, Abun Abun ${ }^{1}$, Muchtaridi Muchtaridi ${ }^{3}$, Ujang Hidayat Tanuwiria ${ }^{1}$ \\ ${ }^{1}$ Faculty of Animal Science, Universitas Padjadjaran, Sumedang - 45363, West Java, Indonesia. \\ ${ }^{2}$ Faculty of Agriculture, Universitas Perjuangan, Tasikmalaya - 46115, West Java, Indonesia. \\ ${ }^{3}$ Faculty of Pharmacy, Universitas Padjadjaran, Sumedang - 45363, West Java, Indonesia.
}

\begin{tabular}{|c|c|}
\hline ARTICLE INFO & ABSTRACT \\
\hline $\begin{array}{l}\text { Received on: } 29 / 10 / 2018 \\
\text { Accepted on: } 12 / 02 / 2019 \\
\text { Available online: } 30 / 03 / 2019\end{array}$ & $\begin{array}{l}\text { The antioxidant compounds in mangosteen peel extract have characteristics, namely, unstable, reactive, and very } \\
\text { easily oxidized. To protect the damage of bioactive compounds, xanthone, it needs a coating method with materials } \\
\text { whose effectiveness and efficiency have been proven such as maltodextrin. This study aims to examine the optimal } \\
\text { formulations and characteristics produced from microencapsulation of mangosteen peel extract with maltodextrin }\end{array}$ \\
\hline $\begin{array}{l}\text { Key words: } \\
\text { Arenga starch, } \\
\text { characterization, } \\
\text { formulation, maltodextrin, } \\
\text { mangosteen peel extract, } \\
\text { microencapsulation. }\end{array}$ & $\begin{array}{l}\text { from arenga starch. The mangosteen peel was extracted with } 96 \% \text { ethanol and maltodextrin was made in microparticle } \\
\text { size. Then, it was formulated in various balances of mangosteen peel extract with maltodextrin, respectively, as } \\
\text { follows: } 70: 30,60: 40,50: 50,40: 60 \text {, and } 30: 70(\%) \text {. Each formulation was homogenized for } 15 \text { minutes and hydrated } \\
\text { for } 18 \text { hours at } 4{ }^{\circ} \mathrm{C} \text {. After that, the sample was homogenized for } 1 \text { minute and sprayed using a spray dryer at a feed rate } \\
\text { of } 15 \mathrm{ml} \text { per minute with an inlet temperature of } 170^{\circ} \mathrm{C} \text { and a pressure of } 1 \text { atm. Furthermore, the microencapsulation } \\
\text { products were carried out by characterization, including particle size, zeta potential, morphology, encapsulation } \\
\text { efficiency, and stability of microcapsules. The data were analyzed using analysis of variance. If there were significant } \\
\text { differences, it would be tested using Duncan's Multiple Range Test method. The results showed that the formulation } \\
\text { of the ratio of mangosteen peel extract with maltodextrin had a significant effect }(p<0.05) \text { on particle size, zeta } \\
\text { potential, morphology, encapsulation efficiency, and stability of microcapsules. The characterization results from each } \\
\text { formulation reported that the ratio of mangosteen peel extract and maltodextrin at level } 50 \%: 50 \%\left(\mathrm{MP}_{3}\right) \text { produced } \\
\text { more proportional characteristics than other treatments. The formulation of mangosteen peel extract with maltodextrin } \\
\text { at a balanced ratio could be used as an alternative supply and processing of functional food. }\end{array}$ \\
\hline
\end{tabular}

\section{INTRODUCTION}

The mangosteen peel extract has the most abundant secondary metabolites compared to other parts of the mangosteen plant, and there are more than 50 types of xanthone contained in each mangosteen rind (Obolskiy et al., 2009). The xanthone content found in the mangosteen fruit plays a role in maintaining various body biological activities such as anti-cancer, anti-bacterial, antiinflammatory, anti-allergic, anti-tumor, anti-hypertensive, antimicrobial, and anti-oxidant (Gutierrez-Orozco and Failla, 2013). Xanthone compounds, as well as other anti-oxidant sources, have

*Corresponding Author

Andri Kusmayadi, Universitas Padjadjaran, Sumedang - 45363, West Java, Indonesia.E-mail: andrikusmayadi1@gmail.com characteristics that are sensitive, unstable, reactive, and easily oxidized (Boots et al., 2008). Therefore, an encapsulation method is needed that can protect important compounds in the mangosteen rind so that it can last long and can still be utilized by the body properly (Semyonov et al., 2010).

The encapsulation method is one of the most widely used techniques to protect bioactive compounds from various environmental factors such as evaporation, oxidation, temperature degradation (Kausadikar et al., 2015), moisture, and light; hence, it can extend the shelf life of the product and avoid damage (Pourashouri et al., 2014). The process of forming encapsulation methods on the scale of microparticles proved to be more effective and efficient, especially in the use of drug doses and the reaction speed in reaching the target cell. One other consideration: 
encapsulation in the size of a microparticle can produce much higher biological values (Ningsih et al., 2017).

Microencapsulation is defined as an essential material packaging technology (core) on the $1-800 \mu \mathrm{m}$ particle scale range, where the core material is protected by matrix material (carrier) to protect the bioactive properties of these important materials both during storage, distribution and application (Adamiec and Modrzejewska, 2004; Kausadikar et al., 2015). Besides needing to pay attention to the protection aspect, the encapsulation method also needs to consider the mechanism to control the release of the core material and cover all unwanted properties of the core material so as not to damage the product (Dubey et al., 2009). The main key to the success of microencapsulation is the selection of coating material because it has an important role in maintaining the stability of microcapsule products. Various types of coatings have been widely used both from polysaccharides, proteins, and lipids (Akdeniz et al., 2017; McNamee et al., 1998) such as gum arabic, stearic acid, gelatin, and maltodextrin (Akhavan et al., 2017; Desai and Park, 2005).

Each coating material has specific physicochemical properties so that it has different structures and characteristics. Coating material must be able to provide a cohesive thin layer with the core material, should mix chemically, but should not react with the core (inert), and should have the properties that are suitable for coating purposes. The number of coatings used can range from $1 \%$ to $70 \%$ and is generally used $3 \%-30 \%$ with a coating wall thickness of 0.1-60 micrometers (Istiyani, 2008). Maltodextrin is widely used as a coating material (Robert et al., 2010) because it has a high level of solubility in water, low viscosity, low sugar content, and colorless (Akhavan et al., 2017). These properties make maltodextrin very suitable to be used as a coating material on herbal extracts such as mangosteen peel (Akdeniz et al., 2017; Sheu and Rosenberg, 1995).

In addition, maltodextrin has excellent properties as a coating material and is proven safe and non-toxic (Ningsih et al., 2017) and the most important is easy to get and the price is affordable. Maltodextrin is an enzymatic and/or acidic hydrolysis product of starch, which consists of a-(1.4) linked D-glucose and/or related polymers, which is usually defined as dextrose equivalent (DE) <20. Maltodextrin can be made from various types of starch sources, but the ones that have been widely used are sourced from cassava (Lambri et al., 2014), corn (Larson et al., 2016), potato (Pycia et al., 2018), and can also be sourced from rice starch (Soe and Than, 2011).

Arenga starch has high potential to be used as raw material for the manufacturing of maltodextrin because the starch content is quite high, reaching $26 \%-37 \%$ in the stem, while the arenga juice ranges from 0.25 to $0.5 \mathrm{~g} / \mathrm{g}$ pith (Manatar et al., 2012). Arenga plant (Arenga pinnata M.) is a plantation crop that is very potential to be developed because it has spread to almost all regions of Indonesia with 14 provinces, which are the centers of arenga sugar development (Effendi, 2010). In addition to the source of coating material, the ratio of the core material to the coating material also determines the characteristics of the microcapsule product that will be produced such as particle size (Akdeniz et al., 2017), particle morphology (Amin et al., 2018), encapsulation efficiency (Akhavan et al., 2017), and microcapsule stability (Mehrad et al., 2015). Therefore, the object of this study aims to examine the formulation of the ratio of the core material with its coating material to the characteristics of the microencapsulation product of mangosteen peel extract with maltodextrin from arenga starch.

\section{MATERIALS AND METHODS}

\section{Materials}

Mangosteen peel, arenga starch, ethanol, amylase enzyme, $\mathrm{HCl}, \mathrm{NaOH}$, methanol, aquabidest, xanthone standards, standard of $\alpha$-mangostin, citric acid, ethyl acetate, tissue paper, sodium acetate, tween 80, artificial intestine fluid (AIF), vortex, analytic scales, particle size analyzer (PSA) "Beckman Coulter LS 13 320," zeta potential analyzer "Beckman Coulter Delsa TM Nano Common Version 2.31/2.03," auto carbon coater (Joel JEC560, Japan), scanning electron microscope "JEOL: JSM-6360 LA," magnetic stirrer (IKA ${ }^{\circledR}$ C-MAG HS7), thermostatic water bath shaking device "JULABO SW," spray drier, rotary evaporator, homogenizer, laminar air flow, milling machine, autoclave, anaerobic incubator, UV spectrophotometer Helios Alpha visible, $\mathrm{pH}$ meter, drop pipette, micropipette, measuring pipette, propipette/rubber suction pump, measuring cup, dissolution tool, water bath, tools diffusion, spectrophotometer (Hitachi U-2810), and ultrasonicator.

\section{Methods}

\section{Microencapsulation of mangosteen peel extract}

Mangosteen peel was extracted using the maceration method by $96 \%$ ethanol solvent for 24 hours (Kusmayadi et al., 2018). Then, maltodextrin was prepared by weighing arenga starch $(15 \% \mathrm{w} / \mathrm{v})$, dissolving with distilled water, and setting the pH using $\mathrm{HCl}$ or $\mathrm{NaOH}$. After that, add $\mathrm{CaCl}_{2} .2 \mathrm{H}_{2} \mathrm{O}$ as much as $40 \mathrm{ppm}$ and the alpha-amylase enzyme according to the desired concentration. Stirring is carried out at a temperature of $87^{\circ} \mathrm{C}$ (to minimize the process of clumping soluble substances in solution) with a rotating speed of 3,000 rpm for 15 minutes. The resulting maltodextrin solution was deactivated by adding $0.5 \mathrm{~N} \mathrm{HCl}$ to $\mathrm{pH}$ \pm 4 . The mangosteen peel extract and maltodextrin, which had been made in microparticle size, were then formulated on various balances of mangosteen peel extract: maltodextrin as follows: 70:30, 60:40 50:50, 40:60, and 30:70 (\%). Each formulation was then homogenized for 15 minutes with a homogenizer and then hydrated for 18 hours at $4{ }^{\circ} \mathrm{C}$. After being homogenized again for 1 minute, the formulation was spray dried using a spray dryer at a feed rate of $15 \mathrm{ml} /$ minute with an inlet temperature of $170^{\circ} \mathrm{C}$ and a pressure of $1 \mathrm{~atm}$. Furthermore, the microcapsule product was tested for its characterization, including particle size, zeta potential, morphology, encapsulation efficiency, and microcapsule stability.

\section{Particle size test and zeta potential microcapsules}

The particle size and zeta potential microcapsules were calculated by dripping the sample on the test equipment. The particle size of the microcapsule product was calculated using a PSA "Beckman Coulter LS 13 320," while the zeta potential value was calculated using the zeta potential analyzer "Beckman Coulter Delsa TM Nano Common Version 2.31/2.03.” 


\section{Microcapsule morphology testing}

Morphology of microcapsules was tested using scanning electron microscopy "JEOL: JSM-6360 LA." Each sample was observed by storing it on a copper grid and then coated carbon with an auto carbon coated tool (Joel JEC-560 produced in Japan) for 5 seconds. Then, the copper grid is inserted into the holder and the sample is ready to be analyzed with a voltage of $120 \mathrm{kV}$ and magnification of $40,000 \times$ (adjusted to the sample conditions).

\section{Microcapsule encapsulation efficiency testing}

The encapsulation efficiency of microcapsule was calculated by measuring free $\alpha$-mangostin (Cf) compared to total $\alpha$-mangostin (Cd). Each microcapsule sample of mangosteen peel extract was taken as much as $10 \mathrm{ml}$ and then put into a separate funnel. Then, added with $10 \mathrm{ml}$ of distilled water, shaken several times, then added $10 \mathrm{ml}$ of ethyl acetate, then shaken and separated the ethyl acetate phase. The filtrate was separated to be measured for its absorption at the wavelength $(\lambda) 319 \mathrm{~nm}$ (maximum scanning results $\lambda$ ) and then included in the standard curve-it will be known the levels of free $\alpha$-mangostin (Cf). Similarly, the total $\alpha$-mangostins content from mangosteen peel extract. Each treatment is repeated five times, and then entrapment efficiency (EE) is calculated by the formula (Widyanati et al., 2014).

$$
\mathrm{EE}(\%)=\frac{(\mathrm{Cd}-\mathrm{Cf})}{\mathrm{Cd}} \times 100 \%
$$

\section{Microcapsule stability testing}

The stability of microencapsulation of mangosteen peel extract-maltodextrin was measured by taking $10 \mathrm{ml}$ of each sample, then inserting it into Erlenmeyer flask and adding artificial intestine fluid (Table 1) until it reached a volume of $100 \mathrm{ml}$, then shaken using a thermostatic water bath shaking device "JULABO SW" until it reached a temperature of $41^{\circ} \mathrm{C}$. The stirrer is run with a stirring speed of $50 \mathrm{rpm}$ for 4 hours. The sampling of $3 \mathrm{ml}$ samples was carried out at $0,1,2,3$, and 4 hours with five replications. A sample of each sample is put into a test tube and then added $3 \mathrm{ml}$ ethyl acetate, then shaken and separated from the ethyl acetate phase. $\alpha$-mangostin, which is released from the microparticle formulation and entered into ethyl acetate, is measured its absorption at a wavelength of $319 \mathrm{~nm}$ and incorporated into the standard curve formula of $\alpha$-mangostin. Thus, the levels of $\alpha$-mangostin free (Cf) and total levels of $\alpha$-mangostin

Table 1. The composition of AIF pH 7.

\begin{tabular}{lcc}
\hline Materials & Amount of salts for 1 L AIF & Concentration (mM) \\
\hline $\begin{array}{l}\text { Sodium hydrogen } \\
\text { carbonate } \mathrm{NaHCO}_{3}\end{array}$ & 1.682 & 20 \\
$\begin{array}{l}\text { Magnesium chloride } \\
\left(\mathrm{MgCl}_{2}\right)\end{array}$ & 0.286 & 3 \\
Kalium chloride $(\mathrm{KCl})$ & 0.373 & 5 \\
Sodium chloride $(\mathrm{NaCl})$ & 7.014 & 140 \\
Calcium chloride $\left(\mathrm{CaCl}_{2}\right)$ & 0.444 & 4 \\
Aquadest & to $1 \mathrm{~L}$ & \\
\hline
\end{tabular}

Source : (Martien et al., 2006). from mangosteen peel extract $(\mathrm{Cd})$ will be known. Microcapsule stability is calculated using the formula below:

$$
\text { Stabilities }(\%)=\frac{(\mathrm{Cd}-\mathrm{Cf})}{\mathrm{Cd}} \times 100 \%
$$

\section{Data analysis}

The results of microencapsulation characterization mangosteen peel extract- maltodextrin from each formulation were tabulated and analyzed using the analysis of variance method with SPSS 21.0. If there is a significant difference, continue with the DMRT method.

\section{RESULTS AND DISCUSSION}

\section{Particle size}

The results of the particle size characterization of the microcapsule products research results are presented in Table 2. The particle size as presented in Table 2 shows that the formulation of mangosteen peel extract-maltodextrin was highly significant $(p<0.01)$ on microcapsule particle size. The balance of mangosteen peel extract as the core material and maltodextrin as coating material affects the microcapsule particle size produced. The percentage of maltodextrin used is higher indicating larger particle size and vice versa. The results of the study in Table 2 show that the particle size produced in this study ranges from 0.2 to $0.8 \mu \mathrm{m}$. These results are in accordance with the microparticle size category according to Chandler et al. (2011) where an object can be said to be micro-sized when in the range of $0.1-1.0 \mu \mathrm{m}$. The particle size on this scale is very good because it has the characteristics of a small microcapsule product that is suitable for the initial purpose of making microencapsulation (Hermanto et al., 2016).

Furthermore, other studies (Akdeniz et al., 2017; Hogan et al., 2001) state that particle size is strongly influenced by the ratio of core material to the coating material. The results of the study (Table 2) show that the more the use of coating materials, the greater the particle size produced. $\mathrm{MP}_{1}$ produces the smallest particle size $(0.236 \pm 0.034 \mu \mathrm{m})$, while $\mathrm{MP}_{5}$ produces the largest particle size $(0.831 \pm 0.122 \mu \mathrm{m})$. The results of this study are in accordance with the research of Akdeniz et al. (2017) who reported that the ratio of core material to coating material at level 1:20 resulted in a smaller size than the ratio of $1: 10$. This is because the $1: 10$ ratio uses more coating material to produce a solution that is very thick and ultimately affects the particle size it produces.

The results of this study are also in accordance with the research of Handayani et al. (2018) who reported that the ratio of dragon fruit extract to maltodextrin greatly affected particle size. The 1:3 ratio has a particle diameter of $0.494-0.770 \mu \mathrm{m}$, while the $1: 5$ ratio has a particle diameter of $0.460-0.611 \mu \mathrm{m}$. These results indicate that the more the maltodextrins used, the greater the particle size. The particle size plays a role in regulating the biodistribution and pharmacokinetics of microcapsules so that they are more effective and efficient in reaching the target cells. By changing the size as small as possible, changing the conformation and microcapsule load also has a good effect on the mechanism 
Table 2. The particle size of the microcapsules product.

\begin{tabular}{ccccccc}
\hline Treatment & $<\mathbf{1 0} \%(\boldsymbol{\mu m})$ & $<\mathbf{2 5} \%(\boldsymbol{\mu m})$ & $<\mathbf{5 0 \%}(\boldsymbol{\mu m})$ & $<\mathbf{7 5 \%}(\boldsymbol{\mu m})$ & $<\mathbf{9 0 \%}(\boldsymbol{\mu m})$ & Mean $(\boldsymbol{\mu m})$ \\
\hline $\mathrm{MP}_{1}$ & $0.061 \pm 0.012$ & $0.070 \pm 0.021$ & $0.084 \pm 0.065$ & $0.215 \pm 0.078$ & $0.749 \pm 0.135$ & $0.236 \pm 0.034^{\mathrm{a}}$ \\
$\mathrm{MP}_{2}$ & $0.054 \pm 0.009$ & $0.064 \pm 0.010$ & $0.080 \pm 0.034$ & $0.630 \pm 0.140$ & $1.923 \pm 0.335$ & $0.473 \pm 0.067^{\mathrm{b}}$ \\
$\mathrm{MP}_{3}$ & $0.054 \pm 0.011$ & $0.064 \pm 0.008$ & $0.081 \pm 0.045$ & $0.618 \pm 0.104$ & $1.999 \pm 0.368$ & $0.486 \pm 0.100^{\mathrm{b}}$ \\
$\mathrm{MP}_{4}$ & $0.063 \pm 0.020$ & $0.142 \pm 0.056$ & $0.562 \pm 0.123$ & $0.744 \pm 0.156$ & $2.091 \pm 0.450$ & $0.709 \pm 0.116^{\mathrm{c}}$ \\
$\mathrm{MP}_{5}$ & $0.077 \pm 0.031$ & $0.109 \pm 0.043$ & $0.460 \pm 0.112$ & $1.758 \pm 0.432$ & $2.150 \pm 0.678$ & $0.831 \pm 0.122^{\mathrm{d}}$ \\
\hline
\end{tabular}

$\mathrm{MP}_{1}: 70 \%$ mangosteen peel extract: $30 \%$ maltodextrin, $\mathrm{MP}_{2}: 60 \%$ mangosteen peel extract: $40 \%$ maltodextrin, $\mathrm{MP}_{3}: 50 \%$ mangosteen peel extract: $50 \%$ maltodextrin, $\mathrm{MP}_{4}: 40 \%$ mangosteen peel extract: $60 \%$ maltodextrin, $\mathrm{MP}_{5}: 30 \%$ mangosteen peel extract: $70 \%$ maltodextrin.

Different superscripts in the same column show highly significant differences $(p<0.01)$.

of action of the product and the nature of microcapsules in the biological environment (Khan et al., 2005). The use of maltodextrin as a coating material has a good role in producing thin and elastic film formation properties, the ability to bind the taste and fat of the product, as well as reducing oxygen permeability of the wall matrix (Sansone et al., 2011).

\section{Zeta potential}

The zeta potential value of the microcapsules product of the research results is presented in Table 3. Statistical data in Table 3 show that the microcapsules of mangosteen peel extract maltodextrin significantly affects the zeta potential value $(p<$ $0.01)$. The zeta potential value is influenced by the percentage ratio of mangosteen peel extract-maltodextrin, in which more addition of maltodextrin gives higher zeta potential value. There was an increase in the zeta potential value which was very sharp in the treatment of $\mathrm{MP}_{1}$ and $\mathrm{MP}_{2}(<1 \mathrm{mV})$ compared to $\mathrm{MP}_{3}-\mathrm{MP}_{5}$ $(>50 \mathrm{mV})$. This shows that the level of microcapsule stability in $\mathrm{MP}_{3}-\mathrm{MP}_{5}$ treatment is higher than $\mathrm{MP}_{1}$ and $\mathrm{MP}_{2}$. These results are consistent with the study of Beck-Broichsitter et al. (2011) who state that high and low zeta potential values (both positive and negative) are stability parameters in microcapsule systems. The higher the zeta potential value, the more the stable the microcapsules produced and vice versa. This is consistent with the opinion of Griffiths et al. (2011) who reported that the zeta potential value in the range of $-30 \mathrm{mV}$ and $+30 \mathrm{mV}$ has very good stability. The zeta potential value with a charge above $\pm 30 \mathrm{mV}$ provides good stability, while a $\pm 20 \mathrm{mV}$ load has shortterm stability and in the range of $-5 \mathrm{mV}$ to $+5 \mathrm{mV}$ shows fast aggregation properties (Honary and Zahir, 2013).

Zeta potential is one indicator of the stability of microparticle suspension, which is determined by the amount of electrostatic interaction between particles. The zeta potential load on microcapsule products as the particle size has an impact on the regulation of the biodistribution and pharmacokinetic properties. The right zeta potential load value can increase the drug release profile and improve product stability in various dosage forms (Honary and Zahir, 2013). High-zeta potential values are useful for minimizing drug delivery aggregation and other pharmaceutical applications (Griffiths et al., 2011). Meanwhile, the low zeta potential charge value allows the particles to pull together and flocculation occurs because of the attraction between Van Der Waal particles. A very positive or negative zeta potential value will cause a greater repulsive force, while repulsion between particles with the same electrical charge will prevent the occurrence of aggregation between particles (Honary and Zahir, 2013; Patil
Table 3. The zeta potential of the microcapsules product.

\begin{tabular}{cc}
\hline Treatment & Zeta potential $(\mathrm{mV})$ \\
\hline $\mathrm{MP}_{1}$ & $+0.14 \pm 0.08^{\mathrm{a}}$ \\
$\mathrm{MP}_{2}$ & $+0.99 \pm 0.16^{\mathrm{a}}$ \\
$\mathrm{MP}_{3}$ & $+53.23 \pm 1.43^{\mathrm{b}}$ \\
$\mathrm{MP}_{4}$ & $+58.07 \pm 2.78^{\mathrm{c}}$ \\
$\mathrm{MP}_{5}$ & $+58.25 \pm 5.63^{\mathrm{c}}$ \\
\hline
\end{tabular}

MP : 70\% mangosteen peel extract: $30 \%$ maltodextrin, $\mathrm{MP}_{2}: 60 \%$ mangosteen peel extract: 40\% maltodextrin, $\mathrm{MP}_{3}: 50 \%$ mangosteen peel extract: $50 \%$ maltodextrin, $\mathrm{MP}_{4}: 40 \%$ mangosteen peel extract: $60 \%$ maltodextrin, $\mathrm{MP}_{5}: 30 \%$ mangosteen peel extract: $70 \%$ maltodextrin.

Different superscripts in the same column show highly significant differences $(p<0.01)$

et al., 2007). This is consistent with other studies which state that the higher the zeta potential value, the greater the electrostatic repulsion between the particles produced and can minimize aggregation or flocculation (Kedar et al., 2010).

The results of the research in Table 3 have zeta potentials, which are all positively charged. This has several advantages as reported by Honary and Zahir (2013) who stated that positively charged microcapsules have advantages in targeted drug delivery systems because the body cell surface is negatively charged. This is because a potential positive zeta can cause stronger electrostatic interactions with mucus or a negatively charged mucosal surface. In addition, the drug delivery system is generally mucoadhesive so that the surface of the positively charged microcapsules can support adhesion to mucosal cells that are negatively charged (Makhlof et al., 2011).

\section{Morphology}

The morphological characteristics of microcapsules show a larger particle size and a tendency for smaller particles to agglomerate. One way to prevent agglomeration is to increase the percentage of coating material (Amin et al., 2018). This is confirmed by the previous study (Cakrawati et al., 2017) that morphological characteristics of limonin microcapsules using maltodextrin are strongly influenced by the ratio of limonin extract to maltodextrin, where the 1:20 ratio shows a more uniform shape than the 1:10 ratio. The morphology of the resulting microcapsules looks like matrix type microcapsules because the protected bioactive compounds in the material coating matrix are maltodextrin. The morphological characteristics of matrix-shaped microcapsules indicate that the microencapsulation process works well. The use of maltodextrin as a low molecular weight coating material can act as a good film coating and plays a role in preventing shrinkage on the surface of microcapsules. Other 


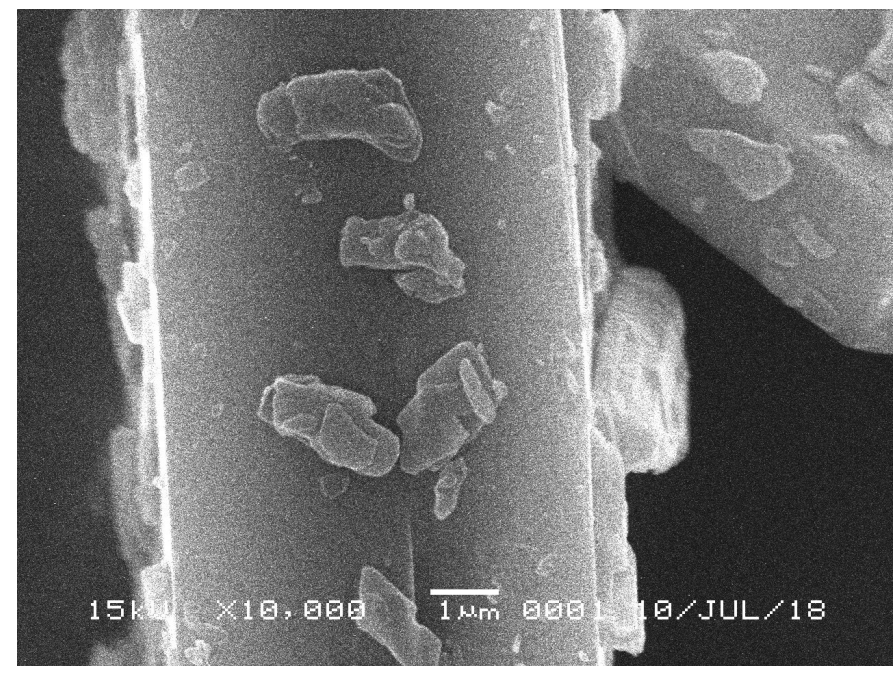

Figure 1. Scanning electron microscope result.

studies report that maltodextrin is a coating material that produces the best morphology because it has the ability to encapsulate better core material (Amin et al., 2018).

The morphology of the particles produced in this study (Fig. 1) looks like an irregular shape or dents. This will adversely affect the activity of microcapsule flow in the cell even though it does not affect its stability (Amin et al., 2018; Finotelli and Rocha-leão, 2005). The outer surface of the microcapsules that looks dented is caused by the shrinkage of particles from droplets during drying and cooling (Amin et al., 2018; Rosenberg et al., 1990). The product characteristics of sprayed microcapsules have morphology such as irregular shapes such as circular shapes, jagged surfaces, cracks, and hollows. The imperfections of microcapsules form occur due to the delay of the film formation process during the drying of droplets of atomized samples (Alves et al., 2017).

\section{Encapsulation efficiency}

The value of encapsulation efficiency of microcapsules products of the research results is presented in Table 4. Encapsulation efficiency values illustrate the ability to encapsulate coating materials on core materials and determine the integrity and porosity of the microcapsule products they produce (Amin et al., 2018; Rosenberg et al., 1990). In addition, encapsulation efficiency has a positive correlation in preventing lipid oxidation and loss of volatile compounds and plays an important role in extending product shelf life (Desai and Park, 2005; Mehrad et al., 2015). Furthermore, Akhavan et al. (2017) report that encapsulation efficiency is strongly influenced by the type of coating material used and the ratio between the core material and the coating material. This is in accordance with the opinion of Jafari et al. (2008) and Mehrad et al. (2015) who report that the main factors that can influence the efficiency of encapsulation are the type of coating material, the nature of the core material (concentration and volatility), emulsion characteristics produced (total solids, viscosity, and droplet size), and conditions during the drying process. In addition, Hogan et al. (2001) and Akhavan et al. (2017)
Table 4. The encapsulation efficiency of the microcapsules product.

\begin{tabular}{cc}
\hline Treatment & Encapsulation efficiency (\%) \\
\hline $\mathrm{MP}_{1}$ & $70.109 \pm 5.870^{\mathrm{a}}$ \\
$\mathrm{MP}_{2}$ & $71.325 \pm 4.002^{\mathrm{a}}$ \\
$\mathrm{MP}_{3}$ & $75.158 \pm 7.413^{\mathrm{ab}}$ \\
$\mathrm{MP}_{4}$ & $77.553 \pm 7.138^{\mathrm{ab}}$ \\
$\mathrm{MP}_{5}$ & $80.409 \pm 4.048^{\mathrm{b}}$ \\
\hline
\end{tabular}

$\mathrm{MP}_{1}: 70 \%$ mangosteen peel extract: $30 \%$ maltodextrin, $\mathrm{MP}_{2}: 60 \%$ mangosteen peel extract: $40 \%$ maltodextrin, $\mathrm{MP}_{3}: 50 \%$ mangosteen peel extract: $50 \%$ maltodextrin, $\mathrm{MP}_{4}$ $40 \%$ mangosteen peel extract: $60 \%$ maltodextrin, $\mathrm{MP}_{5}: 30 \%$ mangosteen peel extract: $70 \%$ maltodextrin.

Different superscripts in the same column show significant differences $(p<0.05)$.

reported that the ratio of the core material and encapsulates have a very large impact on the characteristics of microencapsulation products, especially the efficiency of encapsulation.

The results of the study presented in Table 4 show that microcapsule formulation significantly affected entrapment efficiency $(p<0.05)$. The ratio of the core material and coating material greatly determines the value of encapsulation efficiency. These results are in accordance with the study of Handayani et al. (2018) who reported that the coating ratio had a significant effect on encapsulation efficiency where the ratio of dragon fruit extract to maltodextrin at level 1:10 had a lower EE value $(81.32 \%)$ than ratio $1: 20$ which reached $83.5 \%$. It can be concluded that reducing maltodextrin levels can reduce the efficiency of microcapsule product encapsulation efficiency (Handayani et al., 2018). Other studies (Akhavan et al., 2017) reported that a ratio of $1: 4(25 \%)$ showed the highest efficiency value of anthocyanin encapsulation and increased significantly $(p<0.05)$ compared to a ratio of $12.35 \%$ and $50 \%$. These results are consistent with a previous study that a $25 \%$ ratio is the optimal level in the effective and efficient core material encapsulation process. This shows that a $25 \%$ ratio has better emulsion stability than other ratios both below and above 25\% (Akhavan et al., 2017; Shu et al., 2006).

Other studies (Akdeniz et al., 2017; Cilek et al., 2012; Turasan et al., 2015) report that a 1:10 ratio shows that coating material is insufficient in perfectly covering the core material compared to 1:20 ratio. However, the encapsulation efficiency value of 1:20 is lower than the 1:10 ratio. Increased coating material ratio will reduce the encapsulation efficiency value. Furthermore, Barbosa et al. (2005) and Carneiro et al. (2013) state that the more stable the emulsion of the coating material is used, the higher the encapsulation efficiency value and the more efficient the material to be used. The low encapsulation efficiency value is caused by encapsulation material which is insufficient in producing a strong structural matrix and a protective layer.

One of the disadvantages of maltodextrin is that it has a low emulsifying capacity (Carneiro et al., 2013). Therefore, the percentage value of encapsulation efficiency is in the medium range. Other studies using maltodextrin combined with Arabic gum provide better value for encapsulation efficiency and product stability than using maltodextrin alone (Akhavan et al., 2017). Likewise with studies (Burin et al., 2011) which examined wine anthocyanin encapsulation and roselle encapsulation, Idham et al. (2012) reported that a combination of maltodextrin and 
Table 5. The stability of the microcapsules product.

\begin{tabular}{|c|c|c|c|c|c|c|}
\hline Treatment & 0 hour (\%) & 1 hour (\%) & 2 hours $(\%)$ & 3 hours (\%) & 4 hours $(\%)$ & $\operatorname{Mean}^{\text {ns }}(\%)$ \\
\hline $\mathrm{MP}_{1}$ & $98.129 \pm 0.006$ & $97.920 \pm 0.002$ & $97.249 \pm 0.007$ & $97.248 \pm 0.006$ & $97.003 \pm 0.006$ & $97.510 \pm 0.450$ \\
\hline $\mathrm{MP}_{2}$ & $98.465 \pm 0.002$ & $98.254 \pm 0.019$ & $97.946 \pm 0.010$ & $97.714 \pm 0.002$ & $97.406 \pm 0.004$ & $97.957 \pm 0.397$ \\
\hline $\mathrm{MP}_{3}$ & $99.117 \pm 0.224$ & $98.906 \pm 0.202$ & $98.729 \pm 0.010$ & $98.173 \pm 0.115$ & $97.797 \pm 0.004$ & $98.545 \pm 0.519$ \\
\hline $\mathrm{MP}_{4}$ & $99.111 \pm 0.033$ & $98.879 \pm 0.002$ & $98.600 \pm 0.007$ & $98.207 \pm 0.006$ & $97.963 \pm 0.006$ & $98.552 \pm 0.436$ \\
\hline $\mathrm{MP}_{5}$ & $99.352 \pm 0.179$ & $99.154 \pm 0.023$ & $99.082 \pm 0.047$ & $99.048 \pm 0.069$ & $98.607 \pm 0.061$ & $99.049 \pm 0.265$ \\
\hline
\end{tabular}

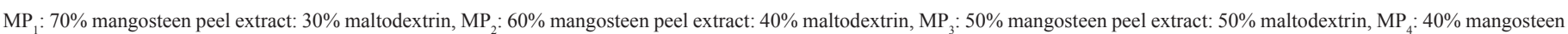
peel extract: $60 \%$ maltodextrin, $\mathrm{MP}_{5}: 30 \%$ mangosteen peel extract: $70 \%$ maltodextrin.

ns: Non significance $(p>0.05)$.

gum Arabic had encapsulation efficiency values which are better because it produces a better structure than maltodextrin alone (Akhavan et al., 2017). However, other studies report that the use of maltodextrin alone without a combination with other ingredients produces the best EE value compared to those combined (Akdeniz et al., 2017).

\section{Stability}

The value of the microcapsule stability of the research results is presented in Table 5. The results of the microcapsule stability test presented in Table 5 reported that microcapsule formulation had no significant effect $(p>0.05)$ on the stability of microcapsules in AIF. Microcapsule stability is strongly influenced by the choice of coating material and the nature of the emulsion (stability, viscosity, and droplet size) (Mehrad et al., 2015). In the manufacture of microencapsulation, the physical and chemical properties of the coating material must be considered because they will affect the efficiency of encapsulation and product stability during storage (Albert et al., 2016; Koç et al., 2015). Maltodextrin has been reported to have better encapsulation efficiency values in anthocyanins and has longer lasting stability (Ravichandran et al., 2014; Robert et al., 2010). Meanwhile, Apintanapong and Noomhorm (2003) and Ravichandran et al. (2014) reported that DE maltodextrin greatly determines the stability of microcapsules in which high DE maltodextrin allows for the formation of encapsulation which has excellent oxidation stability.

This is consistent with the research of Akdeniz et al. (2017) who reported that coating materials have a very important role in determining the stability of encapsulated products. Other studies from Sanchez et al. (2013) reported that maltodextrin as a coating material for encapsulation of red wine polyphenols was able to improve encapsulation stability even though it was stored at $38^{\circ} \mathrm{C}$ for 15 days. Meanwhile, Akhavan et al. (2017) also reported that in addition to coating material factors, the ratio also greatly determines the stability of microcapsule products. The results reported that a ratio of 1:4 $(25 \%)$ resulted in the most stable microcapsules compared to other ratios, both higher and lower than $25 \%$.

\section{CONCLUSION}

The maltodextrin from arenga starch had a good impact on the characteristics of microcapsule products and was in accordance with commercial maltodextrin. The formulation of the level balance of mangosteen peel extract as a core material and maltodextrin as coating material had a significant impact on the characteristics of the microcapsule products produced. The use of mangosteen peel extract and maltodextrin at a balanced level (50\%:50\%) had a proportional characterization result in which particle size, zeta potential, morphology, encapsulation efficiency, and microcapsule stability which was quite good compared to other treatments. Therefore, the formulation of mangosteen peel extract and maltodextrin at 50\%:50\% level is recommended to be used as an optimal formula as a functional food.

\section{ACKNOWLEDGMENTS}

The authors express their gratitude to Endowment Fund for Education, Lembaga Pengelola Dana Pendidikan (LPDP), Ministry of Finance, Republic of Indonesia.

\section{CONFLICT OF INTEREST}

There are no conflicts of interest.

\section{REFERENCES}

Adamiec J, Modrzejewska Z. Sorptivity and structural characteristics of spray-dried chitosan microparticles. In: Proceedings of the 14th International Drying Symposium, pp. 1510-7, 2004.

Akdeniz B, Sumnu G, Sahin S. The effects of maltodextrin and gum arabic on encapsulation of onion skin phenolic compounds. Chem Eng Trans, 2017; 57:1891-6.

Akhavan S, Mahdi S,AssadpoorE, DehnadD. Microencapsulation optimization of natural anthocyanins with maltodextrin, gum arabic and gelatin. Int J Biol Macromol, 2017; 85:379-85.

Albert K, Tóth C, Verasztó B, Vatai G, Koris A. Microencapsulation analysis based on membrane technology: Basic research of spherical, solid precursor microcapsule production. Period Polytech Chem Eng, 2016; 60:49-53.

Alves AI, Rodrigues MZ, Ribeiro Pinto MR, Lago Vanzela ES, Stringheta PC, Perrone ÍT, Ramos AM. Morphological characterization of pequi extract microencapsulated through spray drying. Int J Food Prop, 2017; 20:1298-305.

Amin ZM, Koh SP, Syazwani N, Hamid A, Tan CP. Optimization of spray drying parameters for broken rice maltodextrin powder and its microencapsulation efficiency study on VCO microcapsule. J Nutr Health Food Sci, 2018; 6:1-8.

Apintanapong M, Noomhorm A. The use of spray drying to microencapsulate 2-acetyl-1-pyrroline, a major flavor component of aromatic rice. Int J Food Sci Technol, 2003; 38:95-102.

Barbosa MIMJ, Borsarelli CD, Mercadante AZ. Light stability of spray-dried bixin encapsulated with different edible polysaccharide preparations. Food Res Int, 2005; 38:989-94.

Beck-Broichsitter M, Ruppert C, Schmehl T, Guenther A, Betz T, Bakowsky U, Seeger W, Kissel T, Gessler T. Biophysical investigation of pulmonary surfactant surface properties upon contact with polymeric nanoparticles in vitro. Nanomed Nanotechnol Biol Med, 2011; 7:341-50.

Boots AW, Haenen GRMM, Bast A. Health effects of quercetin: From antioxidant to nutraceutical. Eur J Pharmacol, 2008; 585:325-37. 
Burin VM, Rossa PN, Ferreira-Lima NE, Hillmann MCR, Boirdignon-Luiz MT. Anthocyanins: optimization of extraction from Cabernet Sauvignon grapes, microcapsulation and stability in soft drink. Int J Food Sci Technol, 2011; 46:186-93.

Cakrawati D, Handayani MN, Noor E, Sunarti TC. Morphology and stability of microencapsulation of limonin using maltodextrin: Morphology and stability. IOP Conf Ser Mater Sci Eng, 2017; 180:1-8.

Carneiro HCF, Tonon R V, Grosso CRF, Hubinger MD. Encapsulation efficiency and oxidative stability of flaxseed oil microencapsulated by spray drying using different combinations of wall materials. J Food Eng, 2013; 115:443-51

Chandler WL, Yeung W, Tait JF. A new microparticle size calibration standard for use in measuring smaller microparticles using a new flow cytometer. J Thromb Haemost, 2011; 9:1216-24.

Cilek B, LucaA, Hasirci V, Sahin S, Sumnu G. Microencapsulation of phenolic compounds extracted from sour cherry pomace: effect of formulation, ultrasonication time and core to coating ratio. Eur Food Res Technol, 2012; 235:587-96.

Desai KGH, Park HJ. Recent developments in microencapsulation of food ingredients. Dry Technol, 2005; 23:1361-94.

Dubey R, Shami TC, Bhasker Rao KU. Microencapsulation technology and applications. Def Sci J, 2009; 59:82-95.

Effendi DS. Prospect of aren plant development (Arenga pinnata Merr) supporting bioethanol needs in Indonesia. Perspektif, 2010; 9:36-46.

Finotelli PV, Rocha-leão MHM. Microencapsulation of ascorbic acid in maltodextrin and capsule using spray drying. 2nd Mercosur Congr Chem Eng 4th Mercosur Congr Process Syst Eng, pp. 1-11, 2005.

Griffiths D, Bernt W, Hole P, Smith J, Malloy A, Carr B. Zeta potential measurement of nanoparticles by nanoparticle tracking analysis (NTA). NSTI Nanotech, 2011; 1:4-7.

Gutierrez-Orozco F, Failla ML. Biological activities and bioavailability of mangosteen xanthones: a critical review of the current evidence. Nutrients, 2013; 5:3163-83.

Handayani MN, Khoerunnisa I, Cakrawati D, Sulastri A Microencapsulation of dragon fruit (Hylocereus polyrhizus) peel extract using maltodextrin. IOP Conf Ser Mater Sci Eng, 2018; 288:1-7.

Hermanto RF, Khasanah LU, Kawiji, Atmaka W, Manuhara GJ,

Utami R. Physical characteristics of cinnamon oil microcapsule. IOP Conf Ser Mater Sci Eng, 2016; 107:1-9.

Hogan SA, McNamee BF, O'Riordan ED, O’Sullivan M. Microencapsulating properties of sodium caseinate. J Agric Food Chem, $2001 ; 49: 1934-8$

Honary S, Zahir F. Effect of zeta potential on the properties of nano-drug delivery systems - a review (Part 2). Trop J Pharm al Res, 2013; $12: 265-73$

Idham Z, Muhamad II, Sarmidi MR. Degradation kinetics and color stability of spray-dried encapsulated anthocyanins from Hibiscus sabdariffa L. J Food Process Eng, 2012; 35:522-42.

Istiyani K. Insulin microencapsulation for oral preparation using emulsification method with sodium alginate and chitosan distribution. Thesis, Department of Pharmacy, Universitas Indonesia, Depok, 2008.

Jafari SM, Assadpoor E, He Y, Bhandari B. Encapsulation efficiency of food flavors and oils during spray drying. Dry Technol, 2008; 26:816-35.

Kausadikar S, Gadhave AD, Waghmare J. Microencapsulation of lemon oil by spray drying and its application in flavor tea. Adv Appl Sci Res, 2015; 6:69-78.

Kedar U, Phutane P, Shidhaye S, Kadam V. Advances in polymeric micelles for drug delivery and tumor targeting. Nanomed Nanotechnol Biol Med, 2010; 6:714-29.

Khan MK, Nigavekar SS, Minc LD, Kariapper MS, Nair BM, Lesniak WG, Balogh LP. In vivo biodistribution of dendrimers and dendrimer nanocomposites - Implications for cancer imaging and therapy. Technol Cancer Res Treat, 2005; 4:603-13.

Koç M, Güngör Ö, Zungur A, Yalçın B, Selek İ, Ertekin FK, Ötles S. Microencapsulation of extra virgin olive oil by spray drying: effect of wall materials composition, process conditions, and emulsification method. Food Bioprocess Technol, 2015; 8:301-18.

Kusmayadi A, Adriani L, Abun A, Muchtaridi M, Hidayat UH The effect of solvents and extraction time on total xanthone and antioxidant yields of mangosteen peel (Garcinia mangostana L.) extract. Drug Invent Today, 2018; 10:2572-6.

Lambri M, Dordoni R, Roda A, De Faveri DM. Process development for maltodextrins and glucose syrup from cassava. Chem Eng Trans, 2014; 38:469-74.

Larson ME, Falconer DJ, Myers AM, Barb AW. Direct characterization of the maize starch synthase IIa product shows maltodextrin elongation occurs at the non-reducing end. J Biol Chem, 2016; 291:24951-60.

Makhlof A, Werle M, Tozuka Y, Takeuchi H. A mucoadhesive nanoparticulate system for the simultaneous delivery of macromolecules and permeation enhancers to the intestinal mucosa. J Control Release, 2011; 149:81-8.

Manatar JE, Pontoh J, Runtuwene MJ. Analysis of starch content in stalk aren sugar plant (Arenga pinnata). J Ilm Sains, 2012; 12:89-92.

Martien R, Loretz B, Schnüren AB. Oral gene delivery: design of polymeric carrier systems shielding toward intestinal enzymatic attack Biopolymers, 2006; 83:327-36.

McNamee BF, O'Riordan ED, O'Sullivan M. Emulsification and microencapsulation properties of gum arabic. J Agric Food Chem, $1998 ; 46: 4551-5$

Mehrad B, Shabanpour B, Jafari SM, Pourashouri P Characterization of dried fish oil from Menhaden encapsulated by spray drying. AACL Bioflux, 2015; 8(1):57-69.

Ningsih N, Yasni S, Yuliani S. Nanoparticle of red mangosteen peel extract synthesis and the functional characteristics of its encapsulated products. J Teknol dan Ind Pangan, 2017; 28:27-35.

Obolskiy D, Pischel I, Siriwatanamentanon N, Heinrich M. Garcinia mangostana L.: a phytochemical and pharmacological review. Phyther Res, 2009; 23:1047-65.

Patil S, Sandberg A, Heckert E, Self W, Seal S. Protein adsorption and cellular uptake of cerium oxide nanoparticles as a function of zeta potential. Biomaterials, 2007; 28:4600-7.

Pourashouri P, Shabanpour B, Razavi SH, Jafari SM, Shabani A, Aubourg SP. Oxidative stability of spray-dried microencapsulated fish oils with different wall materials. J Aquat Food Prod Technol, 2014; 23:567-78.

Pycia K, Gryszkin A, Berski W, Juszczak L. The influence of chemically modified potato maltodextrins on stability and rheological properties of model oil-in-water emulsions. Polymers, 2018; 10:1-13.

Ravichandran K, Palaniraj R, Saw NM, Gabr AM, Ahmed AR, Knorr D, Smetanska I. Effects of different encapsulation agents and drying process on stability of betalains extract. J Food Sci Technol, 2014; 51:2216-21.

Robert P, Gorena T, Romero N, Sepulveda E, Chavez J, Saenz C. Encapsulation of polyphenols and anthocyanins from pomegranate (Punica granatum) by spray drying. Int J Food Sci Technol, 2010; 45:1386-94.

Rosenberg M, Kopelman IJ, Talmon Y. Factors affecting retention in spray-drying microencapsulation of volatile materials. J Agric Food Chem, 1990; 38:1288-94.

Sanchez V, Baeza R, Galmarini MV, Zamora MC, Chirife J. Freeze-drying encapsulation of red wine polyphenols in an amorphous matrix of maltodextrin. Food Bioprocess Technol, 2013; 6:1350-4.

Sansone F, Mencherini T, Picerno P, d'Amore M, Aquino RP, Lauro MR. Maltodextrin/pectin microparticles by spray drying as carrier for nutraceutical extracts. J Food Eng, 2011; 105:468-76.

Semyonov D, Ramon O, Kaplun Z, Levin-Brener L, Gurevich N, Shimoni E. Microencapsulation of Lactobacillus paracasei by spray freeze drying. Food Res Int, 2010; 43:193-202.

Sheu T-Y, Rosenberg M. Microencapsulation by spray drying ethyl caprylate in whey protein and carbohydrate wall systems. J Food Sci, 1995; 60:98-103.

Shu B, Yu W, Zhao Y, Liu X. Study on microencapsulation of lycopene by spray-drying. J Food Eng, 2006; 76:664-9. 
Soe HM, Than SS. Observation on the yield of reducing sugar from rice for the preparation of bioethanol by acid hydrolysis. Univ Res J, $2011 ; 4: 431-8$.

Turasan H, Sahin S, Sumnu G. Encapsulation of rosemary essential oil. LWT Food Sci Technol, 2015; 64:112-9.

Widyanati P, Jufri M, Elya B. Formulation and penetration study of liposome gel xanthone of extract mangosteen pericarp (Garcinia mangostana L.). Int J Pharm Sci Rev Res, 2014; 27:1-6.
How to cite this article:

Kusmayadi A, Adriani L, Abun A, Muchtaridi M, Tanuwiria UH. The microencapsulation of mangosteen peel extract with maltodextrin from aren starch: formulation and characterization. J Appl Pharm Sci, 2019; 9(03):033-040. 